\title{
OS VINGADORES: MOBILIZAÇÃO DOS DISCURSOS DA RELIGIÃO, DO MITO, DA TECNOLOGIA, DA HISTÓRIA
}

\author{
THE AVENGERS: LOS VENGADORES: \\ MOBILIZATION OF DISCOURSES MOVILIZACIÓN DE LOS DISCURSOS \\ ABOUT RELIGION, MYTH, DE LA RELIGIÓN, DEL MITO, \\ TECHNOLOGY, AND HISTORY DE LA TECNOLOGÍA, DE LA HISTORIA
}

\author{
Maria Emília de Rodat de Aguiar Barreto Barros* \\ Universidade Federal de Sergipe (UFS), Centro de Educação e Ciências Humanas, \\ Departamento de Letras Vernáculas, São Cristóvão, SE, Brasil
}

\begin{abstract}
Resumo: Este artigo aborda uma pesquisa pós-doutoral, analisando-se discursivamente a filmografia Vingadores. Examinam-se oito sequências enunciativas referentes ao primeiro filme, atentando-se para enunciados concernentes à violência/paz; à verdade/inverdade, ao conhecimento/desconhecimento, fundamentados nas pesquisas arqueológica, genealógica (FOUCAULT). Conforme a primeira, focalizamse dois conceitos basilares: discurso e enunciado, a partir dos quais são estudados o objeto, os campos de saber nele/por ele mobilizados (religião/mito/ufologia; tecnologia/armamentismo; história), averiguandose os acontecimentos em seu entorno. Atinente à genealogia, reflete-se sobre as relações entre poder, produção de verdades homogeneizadoras, capazes de universalizar culturas, modos de vida. Duas perguntas norteiam a análise: qual o papel dos discursos veiculados nesse Universo Cinematográfico para a criação do imaginário dos sujeitos? Num gesto arqueológico, questiona-se a conexão entre a mídia e a história do presente. Constata-se que os Vingadores são considerados pessoas notáveis, rememorando o poder políticoeconômico, armamentista estadunidense, a possível engenhosidade de seus heróis.
\end{abstract}

Palavras-chave: Vingadores. Arqueologia. Genealogia. Discurso.

\begin{abstract}
This paper addresses a postdoctoral research, which discursively analyzes The Avengers, aiming to examine eight enunciative sequences of the movie. Based on the Foucauldian perspective of archaeology and genealogy, we observe utterances regarding violence/peace; truth/untruth, and knowledge/unawareness. In the archaeology, the focus is in two basic concepts: discourse and utterance, where we observe the object, the fields of knowledge mobilized in/by it (religion/myth/ufology; technology/armamentism; history), and study the events around them. Regarding the genealogy, the reflection is on the relations between power and the production of homogenizing truths, as the latter is capable of universalizing cultures and ways of life. Two questions guide the analysis: what is the role of the circulated discourses in this Cinematographic Universe in order to create the subjects' imaginary? In addition, through an archaeological gesture, we question the connection between the media and the history of the present. It is noticeable that the Avengers are remarkable people, resembling the political-economic and arms power of USA, the possible cleverness of their heroes.
\end{abstract}

Keywords: Avengers. Archaeology. Genealogy. Discourse.

* Doutora em Letras (UFBA), Professora Associada do Departamento de Letras Vernáculas da Universidade Federal de Sergipe (UFS), Campus São Cristóvão. ORCID: https://orcid.org/0000-00015287-1949. E-mail: mebarretob@gmail.com. 
Resumen: Este artículo aborda una investigación posdoctoral, analizando discursivamente la filmografía "Vengadores". Objetivase examinar ocho secuencias enunciativas referentes a la primera película, atentando para enunciados concernientes con la violencia/paz; la verdad/falsedad, y conocimiento/desconocimiento, basado en la investigación arqueológica, genealógica (FOUCAULT). Conforme la primera, se enfocan dos conceptos básicos: discurso y enunciado, de los cuales se estudia el objeto, los campos de saber en él/por él movilizados (religión/mito/ufología; tecnología/armamentismo; historia), estudiándose los hechos en su entorno. Relacionado con la genealogía, reflexionase sobre las relaciones entre poder, producción de verdades homogeneizadoras, capaces de universalizar culturas, modos de vida. Dos preguntas orientan el análisis: ¿cuál es el papel de los discursos difundidos en ese Universo Cinematográfico para la creación del imaginario de los sujetos? En un gesto arqueológico, cuestionase la conexión entre los medios de comunicación y la historia del presente. Constatase que los Vengadores son considerados personas notables, rememorando el poder político-económico estadounidense, armamentista, la posible ingeniosidad de sus héroes.

Palabras Clave: Vengadores. Arqueología. Genealogía. Discurso.

\section{INTRODUÇÃO}

Este artigo consiste em resultado parcial do projeto de estudos pós-doutorais, sob o título "Como ler filmes hoje? O Universo Cinematográfico Marvel (Os Vingadores): circulação e reatualização dos discursos" (PPGEdu / UFPE). Nele objetiva-se analisar discursivamente a filmografia de Os Vingadores $^{l}$, fundamentando-se na arqueologia e na genealogia, consoante Michel Foucault.

Conforme a pesquisa arqueológica, procuramos, como ensina Foucault (1997a), delimitar o objeto de estudo, atentando para as relações com diferentes campos do saber, construindo o ponto de vista a partir do qual se dão as abordagens discursivas. Quanto aos campos de saber mobilizados no objeto ("The Avengers", 2012), encontramos a interligação dos discursos religioso/mitológico/ufológico; o discurso tecnológico/armamentista, envolvendo igualmente os conhecimentos referentes à física quântica ${ }^{2}$, à história, os quais constituem a base dos filmes do Universo Cinematográfico Marvel (doravante UCM).

Atinente ao primeiro campo, constatamos um resgate da mitologia nórdica, ao ser retomado o mundo de "Asgard" e seus deuses (Thor, Loki). Igualmente, notamos a presença de naves extraterrestres, reiterando a crença nesses seres (discurso tanto ufológico quanto da física quântica); o discurso religioso judaico-cristão aparece durante remissão a passagens bíblicas, reveladas na análise, além de consistir em um dos suportes da própria história estadunidense.

\footnotetext{
${ }^{1}$ The Avengers (2012); Os Vingadores: Era de Ultron (2015); Os Vingadores: Guerra Infinita (2018); Os Vingadores: Ultimato (2019)

${ }^{2}$ A física quântica estuda todos os fenômenos ocorridos com as partículas atômicas e subatômicas (iguais ou menores que os átomos). Tornou-se base para outros ramos da física, da química. Os seus princípios são aplicados em múltiplos setores do conhecimento humano, revolucionando-se também correntes filosóficas cuja principal ligação está na condição de casualidade e incerteza desta teoria, ao dizer ser possível a existência de duas situações diferentes e simultâneas para determinado corpo subatômico. Esse princípio foi observado na física quântica a partir da chamada "dualidade onda-partícula", quando uma partícula se comporta ora como partícula, ora como uma onda, afirmação totalmente anormal perante a física clássica. Partindo desta ideia, por exemplo, surgem diversas hipóteses teóricas de estudo, como a 'teoria dos vários mundos', afirmando ser possível a existência de diversas realidades alternativas para cada indivíduo. (Significado da Física Quântica: https://www.significados.com.br/fisica-quantica/, adaptado).
} 
O segundo campo do saber (tecnológico/armamentista) é representado pelo arsenal bélico da S.H.I.E.L.D. (Supreme Headquarters of International Espionage and LawEnforcement Division, criado por Stan Lee), apontando para avanços tanto da física quântica quanto da indústria armamentista. Esse arsenal bélico é comparado à competência, ao desenvolvimento dos Chitauri, alienígenas invasores da Terra. O discurso da história, como mencionado, subjaz a toda trama de filmes desse Universo, por remeter não só à segunda grande guerra mundial e, consecutivamente, à guerra fria (marcos fundamentais para a história moderna do ocidente), mas também aos acontecimentos próximos ao lançamento dos filmes. Partindo dessas condições, observando o próprio objeto e relacionando-o aos acontecimentos com os quais traça vizinhanças, separamos, associamos, agrupamos tais discursos, evidenciando alguns deles.

Ainda referente a uma abordagem arqueológica, esclarecemos que Foucault (1997) defende o descentramento do sujeito, consecutivamente, o distanciamento da existência de um sujeito fundador, afastando-se de uma visão embrionária do presente. Tal perspectiva redunda no estabelecimento de novas temporalidades, na busca pela dispersão, pela descontinuidade.

Quanto ao período denominado genealogia, ele consiste, segundo Castro (2016), numa investigação que possibilita o estudo das práticas não discursivas. Esse período está relacionado ao segundo eixo de análise do discurso, conforme Foucault, observando do poder do soberano ao poder disciplinar; da sociedade punitiva à sociedade disciplinar; a organização das técnicas da sociedade disciplinar em instituições como prisões, escolas, fábricas. Em decorrência dessas investigações, Foucault (1997b) defende que o corpo é o alvo da disciplina. Como explica Castro (2016, p. 184-185):

\begin{abstract}
[...] a passagem da arqueologia à genealogia é uma ampliação do campo de investigação para incluir de maneira mais precisa o estudo das práticas não discursivas e, sobretudo, a relação não discursividade/discursividade. Em outras palavras, para analisar o saber em termos de estratégia e táticas ${ }^{3}$ de poder. Nesse sentido, trata-se de situar o saber no âmbito das lutas. [...]. (grifos nossos)
\end{abstract}

Retomando a delimitação do objeto em estudo, ressaltamos que o filme ora analisado rendeu índices bastante relevantes de bilheteria, com um total de arrecadação em torno de 1,519 bilhão USD, levando-o à conquista de prêmios, como o Oscar, o BAFTA (British Academy of Film and Television Arts). "The Avengers" (2012), na cronologia atual do UCM, constitui o sétimo, entre vinte e três filmes lançados, incluindo o mais recente "Homem Aranha: Longe de Casa". São publicações realizadas pela Marvel Entertainment, distribuídas pela Disney e Buena Vista, sob a direção de Joss Whedon, produção de Kevin Feige.

\footnotetext{
${ }^{3}[. .$.$] Foucault introduz uma distinção entre táticas e estratégia: táticas são as racionalidades locais de poder$ em casos particulares; estratégias, por outro lado, são os padrões de poder maiores, sistêmicos ou globais (LYNCH, 2018, p. 39).
} 
Nesse Universo Cinematográfico, notamos uma contraposição entre utopia (numa possível remissão ao modelo de vida estadunidense) e distopia (remissão ao mundo sombrio dos vilões, à maldade, à destruição); violência e paz; subjugação e resistência; conhecimento e desconhecimento. No presente estudo, analisamos oito sequências enunciativas (SE), entre as quais duas se referem aos acontecimentos ocorridos próximos ao lançamento do filme; seis foram retiradas do filme, observando-se as relações de poder/saber, poder/verdade, poder/subjetivação; os campos de saber mencionados. Similarmente, conforme a definição de dispositivo discursivo, consoante Deleuze (2015), Foucault (2008) e Gregolin (2016), consideramos esse filme um dispositivo discursivo de poder, por meio do qual é construída uma "história do presente". Tal consideração justifica-se por esse objeto de estudo consistir em um acontecimento, revelando uma tensão entre memória e esquecimento.

Quanto aos campos de saber anteriormente elencados, entendemos que, por constituir interface entre o discurso religioso e o mítico, esse Universo Cinematográfíco remonta ao dualismo "bem versus mal", na medida em que seus habitantes são deuses, super-heróis, humanos, alienígenas. No eixo do bem, encontram-se os personagens supostamente contrários à violência, à morte, com vistas ao alcance da paz, à detenção do poder/saber/verdade, numa remissão aos discursos propagados não só na história estadunidense como na história ocidental do presente. No eixo do mal, alienígenas lutam pelo domínio tanto da Terra como do Universo. Esse gesto de possível combate ao mal remete à guerra fria, quando as Histórias em Quadrinhos (mais adiante, HQs), fonte de inspiração dos filmes, surgiram. Apesar de sua origem, os filmes não consistem em uma continuação delas; há outros produtores, roteiristas à sua frente, implicando um processo constante de (res)significação. No filme, como ensina Bernadet (1985), as imagens encontram seu suporte na mídia cinematográfica, cuja linguagem é uma sucessão de seleções, de escolhas, uma expressão de montagem. Isso determina o processo de manipulação concernente a essa mídia, conferindo ao cinema uma linguagem produtora de sentidos, porém não necessariamente reprodutora do real.

Similarmente, esse dualismo (bem versus mal) remete à recente história estadunidense, relacionada à guerra travada contra o Iraque. Por revelar tais fatos históricos, há grande divulgação do poder estadunidense enquanto protetor dos valores, modos de vida do ocidente, responsável por sua universalização. Em virtude disso, inspira os espectadores do mundo a pensarem nesse projeto de sociedade como um modelo a ser seguido, com o subsequente processo de homogeneização da história do presente, em relação a múltiplos povos e culturas.

Para esclarecer a formulação deste trabalho, afora esta introdução e as considerações finais, elaboramos três itens: 2. O Universo Cinematográfico Marvel, uma apresentação desse Universo, breves considerações relacionadas ao filme. 3. Da teoria às análises, um olhar discursivo, ao longo do qual discutimos os principais conceitos de Foucault, referentes ao dispositivo, ao discurso, ao acontecimento, ao enunciado, ao poder. No decorrer dessa discussão, analisamos cinco sequências enunciativas, tentando relacionar a teoria ao objeto de estudo. No item 4, intitulado Conhecimento, verdade, poder, subjetivação, investigamos a relação poder/saber/verdade/subjetivação, conforme Foucault. Ao longo deste item, analisamos três sequências enunciativas. 


\section{O UNIVERSO CINEMATOGRÁFICO MARVEL}

O Universo Cinematográfico, como afirmado, está povoado por super-heróis. A história de "Os Vingadores" apresenta vários deles, entre os quais estão Homem de Ferro (Tony Stark; doravante, HF), Hulk, Thor e Loki ${ }^{4}$. Os dois últimos são migrados do campo de saber da mitologia nórdica: o primeiro, o deus do trovão, representante da força da natureza; o segundo, Loki, irmão adotado de Thor, um deus/gigante, ligado à magia, símbolo da maldade e traição, considerado como uma das figuras mais complexas dessa mitologia; na trama, surge como um dos principais vilões. No filme, assim como os outros personagens, Thor simboliza o herói, protetor essencialmente da Terra, sugerindo uma comparação entre super-heróis e deuses mitológicos; há, portanto, uma mudança de posição discursiva desse personagem (de deus mitológico a super-herói). Nesse contexto, ao mesmo tempo que observamos essa mudança de posição, verificamos o discurso sobre o mito, numa demonstração do poder dos deuses contrapondo-se à fragilidade dos homens. Além desses personagens, neste filme, estão presentes Capitão América, Viúva Negra, Gavião Arqueiro ${ }^{5}$. O Capitão também rememora a segunda guerra mundial, época de seu surgimento, na HQ.

Numa tentativa de sumarizar o enredo deste filme, objetivando situar o leitor não conhecedor dessa filmografia, mencionamos os principais momentos dessa película, ainda numa perspectiva discursiva: o filme tem início com Nick Fury (Samuel L. Jackson), diretor da S.H.I.E.L.D., reunindo os super-heróis apresentados anteriormente (no dizer do HF, aos (01:41: 31): "Os heróis mais poderosos da Terra [...]"), para enfrentarem a vilania de Loki e seu exército alienígena, cujo objetivo era governar os humanos, subjugando-os. Fury é contactado por Phil Coulson (Clark Gregg), considerado braço direito desse diretor; vai ao centro de pesquisas da SHIELD, onde cientistas, a exemplo do doutor Erik Selvig (Stellan Skarsgard), haviam detectado o funcionamento voluntário do Tesseract (nesse Universo, um instrumento que provoca a luta entre a SHIELD e a HIDRA, desde o filme "Capitão América: O Primeiro Vingador" (2011)). Esse objeto é fonte de energia de potencial desconhecido. Seu funcionamento resultou na abertura de um portal, do qual Loki ressurgiu, após o exílio iniciado no filme "Thor" (sexto filme), continuando as histórias anteriormente narradas na filmografia do UCM. Após uma luta travada contra os guardiões do centro de pesquisa, Loki obtém o Tesseract, tão almejado por ele e pelos Chitauri. Para tal, utilizando seu cetro (arma de Loki), controla as mentes de várias pessoas da S.H.I.E.L.D., entre as quais se encontram o Gavião Arqueiro e o cientista, já mencionado. Por conta disso, a Iniciativa Vingadores (planejada desde o filme "Capitã Marvel" ") é acionada, reunindo os super-heróis, no dizer de Fury, "pessoas notáveis", revelando uma associação com a coragem, a força, o conhecimento, numa oposição à vulnerabilidade do ser humano.

\footnotetext{
${ }^{4}$ Esses personagens são interpretados, respectivamente, por Robert Downey Jr., Mark Ruffalo, Chris Hemsworth, Tom Hiddleston.

${ }^{5}$ Sequencialmente, interpretados por Chris Evans, Scarlett Johansson (numa remissão à aranha), Jeremy Renner.

${ }^{6}$ Este filme, apesar de ter sido lançado em 2019, constitui o segundo filme da filmografia Marvel, após o "Capitão América: O Primeiro Vingador" (2011).
} 
Durante seu exílio, Loki se alia aos Chitauri, como mencionado, alienígenas cujo propósito era a conquista do Universo, a partir do Tesseract, em troca do qual esse povo concorda em permitir que Loki governe a Terra. Os Vingadores, então, empenham-se em impedir a realização do objetivo de Loki e dos Chitauri, numa guerra épica entre humanos, super-heróis, deuses nórdicos, alienígenas. Tudo isso em meio a um requinte tecnológico de grandes proporções, administrado, principalmente, pelo Homem de Ferro. A constante visibilidade de alienígenas, deuses mitológicos evidencia o discurso sobre a possível existência de vida em outros planetas, numa remissão tanto ao discurso ufológico (e, nessa medida, ao discurso da física quântica), quanto ao religioso, quando traz à tona as palavras bíblicas, segundo as quais "Na casa do meu Pai, há muitas moradas [...]" (João $14: 2)$.

No final, o HF desponta como o grande herói da história, ao levar o míssil lançado sobre Nova Iorque até a nave mãe dos Chitauri, destruindo, assim, o exército alienígena, ao mesmo tempo em que a Viúva Negra consegue fechar o portal de acesso dos alienígenas à Terra, numa possível demonstração do empoderamento feminino. Nesse espaço de tempo, o HF consegue voltar à Terra, em queda livre; entretanto, sua queda é amortizada por Hulk, demonstrando a força desse super-herói. Finalizada a batalha, o Tesseract é entregue a Thor, que volta para Asgard com Loki, como prisioneiro. Os demais seguem suas vidas.

\section{DA TEORIA ÀS ANÁLISES, UM OLHAR DISCURSIVO}

Na breve exposição desse enredo e da fundamentação teórica do trabalho, na análise apresentada a seguir concordamos com Foucault (2003), segundo o qual, para se compreender os discursos, é importante acionar os acontecimentos em sua volta, seu processo de construção de sentidos. Consoante suas pesquisas, a análise de discurso compreende dois níveis: em um determinado nível, conjunto regular de fatos linguísticos (principalmente se são levados em conta os estudos presentes em As palavras e as coisas); no outro, polêmicos e estratégicos. Foucault ([1973] 2013, p. 19) propõe uma análise de discurso nos seguintes termos:

[...] não mais sob os aspectos linguísticos, mas, de certa forma [...] como jogos (games), jogos estratégicos, de ação e de reação, de pergunta e resposta, de dominação e de esquiva, como também de luta. O discurso é esse conjunto de fatos linguísticos em determinado nível, e polêmicos e estratégicos em outro.

Objetivando a análise discursiva, principalmente voltada para o segundo nível de análise, duas perguntas a norteiam: qual o papel dos discursos veiculados no UCM para a criação do imaginário dos sujeitos? Num gesto arqueológico, questionamos a conexão entre a mídia e a 'história do presente'. Consideramos também o conceito foucaultiano de enunciado, materializado em forma de qualquer registro. De acordo com Foucault (1997a), com a análise dos enunciados, não se pretende uma descrição total, exaustiva da 'linguagem' ou de 'o que foi dito'. Segundo esse filósofo (1997, p. 104 - 105): “[...] a descrição do nível enunciativo [...] pode ser feita [...] pela análise das relações entre o 
enunciado e os espaços de diferenciação, em que ele mesmo faz aparecer as diferenças". Para Gregolin (2011, p. 86): “[...] o ‘enunciado', na análise arqueológica de Foucault, não é exclusivamente linguístico, tem natureza semiológica”. Ainda consoante Gregolin (2011, p. 87): "[...] a 'semiologia' pensada por Foucault tem natureza essencialmente histórica".

No que concerne à mídia, em geral; à cinematográfica, em particular, como mencionado, observando os fundamentos de Deleuze (2015), Foucault (2008), Gregolin (2016), categorizamos essa mídia como um dispositivo de poder. Consoante Foucault (2008, p. 244), os dispositivos são heterogêneos: "“...] engloba(m) discursos, instituições, organizações arquitetônicas, decisões regulamentares, leis, medidas, enunciados científicos, proposições filosóficas, morais, filantrópicas". Em outros termos, o dispositivo incorpora o dito e o não dito, o dizer e o fazer; constitui uma rede interligando todos esses elementos. Essas redes estão relacionadas ao poder, (re)produzindo saber. Como ensina Gregolin (2016), o dispositivo é concebido como uma tática, uma estratégia correspondendo a uma certa necessidade histórica, de um certo momento histórico.

Deleuze (2015), revisando o conceito de dispositivo na obra de Foucault, defende que um dispositivo é caracterizado por três dimensões: a primeira se refere ao conceito segundo o qual todo dispositivo tem suas curvas de visibilidade, relacionadas, principalmente, aos estudos derivados do Panóptico de Bentham, primordialmente ao "par ver ser visto" visibilidade cinematográfica pode ser percebida, inicialmente, pelo quantitativo de espectadores que assistiram à trama, resultando em uma geração de altos índices de bilheteria $^{8}$. Para além dessa perspectiva, atentamos para a existência das curvas de visibilidade, quando levamos em conta a conexão atores/atrizes e público alvo que, apesar do afastamento físico, pode ser identificada se se considerar o advento das redes sociais. É importante ainda observar o fato de esse filme ser exibido reiteradas vezes, tanto pelas televisões fechadas como pelas abertas, além das plataformas de streaming ${ }^{9}$ que disponibilizam essa filmografia; dos DVDs. Em virtude disso, os campos de saber, apontados na introdução, são largamente expostos, primeiramente, numa determinada medida; depois, em múltiplos meios midiáticos.

A segunda dimensão refere-se à enunciabilidade: todo dispositivo apresenta um aspecto de um dizer excessivo, na mesma medida em que o apaga. Esse jogo entre o dizer e o não dizer dos enunciados produz as curvas de enunciabilidade, conforme Deleuze (2015). Atinente a essa dimensão, compreendemos que a própria estrutura narrativa, no blockbuster, é responsável por esse movimento de dizer e apagar, na medida em que as histórias são apresentadas como lineares. Mas, ao relacioná-las com os acontecimentos com os quais traça vizinhanças, numa perspectiva da história, da política, da economia, observamos, igualmente, o apagamento das discussões concernentes a esses campos do saber.

7 “O Panóptico é uma máquina de dissociar o par ver-ser visto: no anel periférico, se é totalmente visto, sem nunca ver; na torre central, vê-se tudo, sem nunca ser visto" (FOUCAULT, 1997b, p. 167).

${ }^{8}$ Como mencionado, só no Brasil, a bilheteria de Os Vingadores (2012) atingiu 10.968.065 ingressos vendidos (http://www.adorocinema.com/slideshows/filmes/slideshow-138826/\#page=9, acessado em 07/12, às 00:32).

${ }^{9}$ Desde dezembro de 2020, toda a produção da Marvel está locada no streaming Disney. Nele se pode encontrar todos os filmes do Universo Cinematográfico Marvel. 
Fundamentado nessas duas dimensões (visibilidade e enunciabilidade), Deleuze (2015) afirma que os dispositivos têm seus regimes de luz, os de dizibilidade; pois, de certa maneira, torna algo muito visível, mas, ao mesmo tempo, oculta outras coisas. Isso resulta do fato de, em todo dispositivo, o dito e o mostrado serem controlados pelos poderes. Como consequência, a terceira dimensão dos dispositivos se relaciona com esse controle: as linhas de força, capazes de controlar a visibilidade e a dizibilidade; consistem nos poderes controladores daquilo que se pode ou não dizer. Nessa direção, compreendese que, no que se refere às linhas de força, considerando o controle dos discursos divulgados pela mídia, há uma relação com a interdição dos discursos. E, em decorrência dessa interdição, ocorrem as chamadas linhas de fuga (FOUCAULT, 2008).

Tais linhas correspondem ao que Deleuze (2015) considera como a quarta dimensão de um dispositivo: as linhas de subjetivação, pois surgem como efeito dos jogos entre o dizer, o mostrar, o ocultar. Essa subjetivação produzida pelos dispositivos apresenta-se em movimento. Quanto ao filme analisado, o processo de subjetivação pode ser constatado pelas interações entre os apaixonados pelo UCM, nos ciberespaços, tais como Instagram, Facebook, Youtube, por exemplo. Pensando com esses autores, percebemos que a mídia cinematográfica consiste em um dispositivo de poder, por ela, na medida em que veicula discursos institucionalmente marcados, constituir uma rede capaz de interligar os elementos a que Foucault (2008) se refere: discursos, instituições, organizações arquitetônicas etc.

Ainda no que concerne à mídia cinematográfica, atentamos para seu poder, ao reatualizar os discursos em geral; em particular, os rememorados em "Os Vingadores" (2012): o discurso religioso, o mitológico, o ufológico; o tecnológico/armamentista; o da história. Por conseguinte, a mídia instaura novos discursos acerca de determinados objetos; na mesma medida, ela se esforça para a perpetuação de mesmos discursos, apontando para um movimento entre o mesmo e o outro. De igual modo, tais discursos entram em um novo processo de produção de sentidos, enquanto um acontecimento, pois são reatualizados em momentos diferentes, na medida em que os filmes são exibidos várias vezes. Tal gesto provoca uma grande movência de sentidos.

Continuando essa discussão, retomamos os eixos investigativos com os quais Foucault trabalha no desenvolvimento de suas pesquisas: a relação poder/saber/verdade/subjetivação. Para Foucault ([1973] 2013, p. 10), o poder não se resume ao Estado, encontra-se em toda parte, é tentacular: "[...] é, ao mesmo tempo, econômico, político, judiciário e epistemológico". Daí esse filósofo discordar do marxismo no que diz respeito à política, à ideologia, pois Foucault ([1977] 2012) considera que o marxismo trata tais instâncias como superestruturais. Como resultado dessa discordância, uma análise discursiva pautada nesse filósofo não consiste em uma análise materialista do discurso, pois ele mesmo nega situar na base do sistema as forças produtivas; para Foucault, há relações muito mais complexas que ligam a tecnologia do poder e o desenvolvimento das forças produtivas (FOUCAULT, [1977] 2012).

Quanto à subjetivação, Foucault ([1973] 2013) defende que a constituição do sujeito ocorre no interior da história, haja vista seu viés arqueológico de pesquisa, utilizado com vistas a indagar como o homem constrói sua própria existência. Nesse sentido, os sujeitos, os objetos são construídos discursivamente partindo-se do que se fala 
sobre eles. Ainda segundo Foucault ([1973] 2013, p. 18), “[...] O próprio sujeito do conhecimento tem uma história, a relação do sujeito com o objeto, ou, mais claramente, a própria verdade tem sua história". Esse filósofo busca observar "[...] a constituição histórica de um sujeito do conhecimento através de um discurso tomado como um conjunto de estratégias que fazem parte das práticas sociais" (FOUCAULT, ([1973] 2013, p. 20). Com efeito, o sujeito se constitui no interior da história e, a cada instante, é fundado, refundado por ela.

A essa teoria, acrescentamos que, como define Foucault ([1978] 2012, p. 248), o discurso deve ser tratado como "[...] uma série de acontecimentos, como acontecimentos políticos, através dos quais o poder é vinculado e orientado”. Em decorrência dessa definição, o referido filósofo nega a relação do discurso com a estrutura, ao mesmo tempo em que esclarece o conceito de acontecimento:

\begin{abstract}
Eu me dei como objeto uma análise do discurso [...]. Meu programa não se fundamenta tampouco nos métodos da linguística. A noção de estrutura não tem nenhum sentido para mim. O que me interessa, no problema do discurso, é o fato de que alguém disse alguma coisa em um dado momento. Não é o sentido que eu busco evidenciar, mas a função que se pode atribuir uma vez que essa coisa foi dita naquele momento. Isto é o que eu chamo de acontecimento. (FOUCAULT, [1978] 2012, p. 249) (grifos nossos)
\end{abstract}

Ao considerar o discurso como uma série de acontecimentos, o pesquisador cujo aporte teórico se centra nos estudos discursivos foucaultianos coloca-se igualmente na dimensão da história, na medida em que, tal como Foucault ([1978] 2012, p. 231) argumenta, busca entender "[...] por que e como se estabelecem relações entre os acontecimentos discursivos". Tais acontecimentos não devem estar, necessariamente, relacionados a longos períodos, como faziam os historiadores, crédulos em uma história global (FOUCAULT, 1997a). Mas, numa perspectiva de uma história geral, tais períodos podem se referir a diferentes temporalidades. Ainda no que concerne ao discurso, conforme esse filósofo ([1976] 2011, p. 220 - 221), ele é considerado como um campo estratégico, um operador, em direção ao segundo nível de análise:

[...] o discurso não deve ser compreendido como o conjunto de coisas que se diz, nem como a maneira de dizê-las. Ele está igualmente no que se diz, ou que se marca por gestos, atitudes, maneiras de ser, esquemas de comportamentos, manejos espaciais.

Trata-se, aqui, de mostrar o discurso como um campo estratégico no qual os elementos, as táticas, as armas não cessam de passar de um campo ao outro, de permutar-se entre os adversários, de voltar-se contra os que os utilizam. É à medida que ele é comum que o discurso pode tornar-se a um só tempo num lugar e um instrumento de confronto.

$[\ldots]$

O discurso é para a relação das forças não apenas uma superfície de inscrição, mas um operador.

Ao compararmos o discurso com um campo estratégico, estamos relacionando o discurso à história, aos processos de constituição dos sujeitos, ao político, ao social, enquanto um processo histórico-discursivo. É nesse contexto que recorremos a uma análise arqueológica, em consonância com a qual observamos o discurso, o enunciado. É assim que Foucault (1997a, p. 32) define enunciado: 
[...] um enunciado é sempre um acontecimento que nem a língua nem o sentido podem esgotar inteiramente. Trata-se de um acontecimento estranho, por certo: [...], abre para si mesmo uma existência remanescente no campo de uma memória, ou na materialidade dos manuscritos, dos livros e de qualquer forma de registro; em seguida, porque é único como todo acontecimento, mas está aberto à repetição, à transformação, à reativação; finalmente, porque está ligado não apenas a situações que o provocam, e a consequências por ele ocasionadas, mas, ao mesmo tempo, e segundo uma modalidade inteiramente diferente, a enunciados que o precedem e o seguem. (grifos sublinhados nossos)

Conforme tal definição, consideramos o filme "Os Vingadores" um enunciado, em que há, como mencionado, a todo momento, tanto uma retomada de enunciados que o precedem, como uma remissão a novos enunciados, os quais, geralmente, são pontuados em cenas pós-crédito. Ademais, ambas as relações enunciativas são vinculadas não só à trama desse mesmo Universo como à história estadunidense do presente, do passado. Em consequência desse jogo enunciativo, no decorrer do enredo, observamos um processo constante de reatualização de discursos. Esclarecemos que, sob o ponto de vista de Foucault ([1969], 2009, p. 284): ela (a reatualização) consiste na “[...] reinserção de um discurso em um domínio de generalização, de aplicação ou de transformação que é novo para ele".

Adotamos, então, esse olhar arqueológico, atentando para os enunciados precedentes, subsequentes, simultâneos ao lançamento do filme, a fim de analisar as sequências enunciativas retiradas do objeto. Primeiramente, retomamos a tragédia histórica vivenciada pelo povo estadunidense, por ocasião do atentado às Torres Gêmeas, ocorrido em 11 de setembro de 2001. Enfatizamos o gesto de luta (ou de vingança?) e de luto desse povo a partir desse atentado, um acontecimento ocorrido na cidade de Nova Iorque, em pleno centro econômico-financeiro dos Estados Unidos.

Em segundo lugar, lançamos mão de uma reportagem, publicada em 26 de abril de 2012, pelo Instituto Humanitas Unisinos, baseada no artigo de Santiago O'Donnell, intitulado "Desigualdade: lições latino-americanas para os Estados Unidos". Tal reportagem situa o leitor em relação à sociedade estadunidense em 2012, ano do lançamento deste filme ( 27 de abril de 2012). Ela apresenta dados de pesquisa que revelam a desigualdade social estadunidense, sinalizando para o fim do sonho americano. Mas, mesmo vítima de políticas públicas ineficientes, pondo em risco a realização desse sonho, o povo reelege o presidente Barack Obama.

Relacionando esses dois acontecimentos históricos ao objeto em análise, sob o prisma arqueológico, entendemos que a história dos personagens, na batalha épica contra os vilões alienígenas, traz à tona a necessidade de se acreditar na vitória do bem (em conformidade com o entendimento desse povo e sua posterior divulgação), no recrudescimento do ideal americano. De igual modo, revela a capacidade de os heróis se vingarem desse mal - nesse caso, da invasão alienígena.

$\mathrm{E}$, ainda atentando para tais acontecimentos, analisamos abaixo duas sequências enunciativas: a primeira ( $\mathrm{SE}_{1}$ ) é a imagem do Memorial 11 de setembro (em inglês, "9/11 Memoria \& Museum”), aberto ao público em 11 de setembro de 2011, dez anos após o ataque às Torres Gêmeas. Comparamos essa imagem à cena de 'Os Vingadores' $\left(\mathrm{SE}_{2}\right)$, em que o Homem de Ferro leva o míssil para o portal aberto pelo Tesseract, rumo à nave mãe, salvando a cidade de Nova Iorque de uma destruição por esse objeto bélico. 


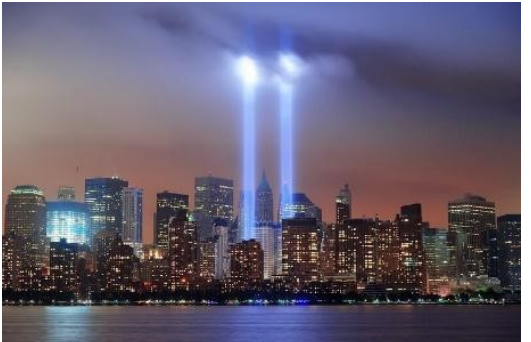

Figura 1 - SE1 - Imagem: monumento ao 11 de setembro de 2001: "Tribute in light"

Fonte: Inauguração do monumento 11 de setembro. Disponível em:

https://sicnoticias.pt/mundo/2017-09-11-Ja-passaram16-anos-desde-o-11-de-Setembro. Acesso em: 12 de dezembro de 2019.

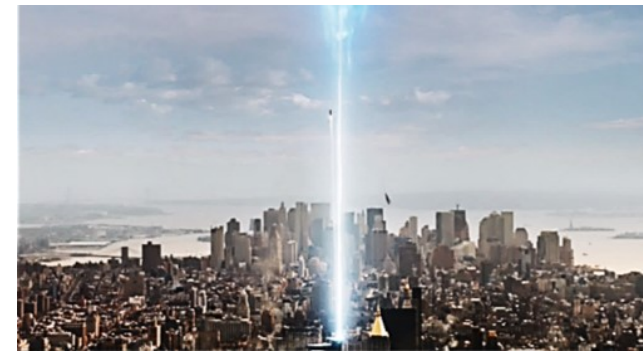

Figura 2 - SE2 (2:06:00): Cena do Homem de Ferro rumo à nave mãe dos Chitauri, invasores alienígenas

Fonte: OS VINGADORES: The Avengers.

Direção Joss Whedon. Marvel Entertainment:

Disney e Buena Vista. USA, 2012. [DVD]

$2 \mathrm{~h} 23 \mathrm{~min}$, colorido.

Postas lado a lado, essas duas imagens dialogam histórica e discursivamente, numa produção de novos sentidos: vitória, força, coragem, heroísmo. São as luzes lançadas da cidade de Nova Iorque, rumo ao espaço: as primeiras, a partir de um novo lugar criado para, ao mesmo tempo, lembrar e apagar a tragédia ocorrida nessa cidade, resultante de ataque terrorista; a segunda, num gesto de defesa da cidade, a luz que dá visibilidade ao super-herói novaiorquino, Tony Stark (HF), representante de uma elite tanto intelectual quanto financeiramente abastada. Enfatizamos ainda o local, o estabelecimento de interrelações dos dois acontecimentos: a cidade de Nova Iorque, ambos ligam céu, Terra, luz, rememorando a simbologia religiosa.

Ainda com vistas à associação entre Os Vingadores e o discurso religioso, precedendo a $\mathrm{SE}_{2}$ (representada na Figura 2), há um diálogo entre o Homem de Ferro e a inteligência artificial, Jarvis, em que este adverte aquele:

$\left(\mathrm{SE}_{3}(2: 01: 25)\right)$ - J: Senhor, ficaremos sem energia antes de penetrarmos naquele caso....

H.F: Jarvis, conhece a parábola de Jonas?

J. Eu não o consideraria um exemplo.

Verificamos, no diálogo da $\mathrm{SE}_{3}$, a reatualização do discurso religioso judaicocristão, no qual a cultura ocidental, em geral e, em particular, a estadunidense estão fundamentadas. Quando o HF se refere à parábola de Jonas, ele remete os espectadores ao Antigo Testamento, ao livro de Jonas, que consiste em um relato biográfico desse profeta, numa ilustração de misericórdia de Javé aos ninivitas. Javé, representante de um Deus de toda a humanidade, em vez da destruição do povo, deseja sua conversão. Essa parábola revela que Deus deseja a salvação também dos pagãos, daqueles tratados como inimigos. Dessa remissão resulta o apagamento do discurso acerca de um Deus vingador, propalado, principalmente, durante a Idade Média. E, ao ser incorporada pelo HF, esse apagamento reflete semelhantemente na imagem dos super-heróis, justificando o gesto de destruição da nave mãe inimiga. A vingança é interpretada como justiça - afinal, como 
bem adverte o HF, em diálogo com Loki: se os heróis não conseguem proteger a Terra, eles a vingam $(01: 41: 31)^{10}$.

Num olhar para a história passada estadunidense, semelhantemente observamos uma remissão à doutrina do destino manifesto, consoante o qual o povo americano foi eleito por Deus para civilizar a América. Esse processo civilizatório redunda na Guerra da Secessão (1861 a 1865), quando o Norte foi vitorioso, impedindo a separação do país, exterminando (em tese) a escravatura nesse país. No final do século XIX, sua economia tornou-se a maior do mundo, e o país expandiu-se para o Pacífico.

Se confrontarmos esses discursos com o contexto sociopolítico, histórico em que o filme foi lançado, observamos a tensão entre memória e esquecimento, sobre a qual falamos na introdução: nesse caso particular, a guerra é contra os alienígenas, e Stark repete o gesto de Jonas, ao adentrar o portal, a fim de impedir a destruição dos novaiorquinos; há também a libertação dos humanos de uma possível escravidão instaurada, dessa vez, por alienígenas. Em tese, o desenvolvimento da trama, as imagens associadas a ela possibilitam a compreensão de que houve justiça.

No seguimento da análise, retomamos a ligação estabelecida entre o conceito de dispositivo e a mídia cinematográfica. Considerando o dispositivo como uma estratégia proveniente de uma necessidade histórica, observamos o dito e o não dito, corporificados nas imagens do filme ora examinado. Ainda no que diz respeito à comparação entre o ataque de alienígenas à cidade de Nova Iorque e o ataque terrorista às Torres Gêmeas, constatamos uma estreita relação entre eles, nas duas sequências enunciativas abaixo expostas. As $\mathrm{SE}_{4}$ e $\mathrm{SE}_{5}$, assim aproximadas, obedecem ao regime de luz, consoante Deleuze (2015), na medida em que há, ao mesmo tempo, uma exposição excessiva e um apagamento obsessivo desses discursos. Afinal, "Os Vingadores" (castigadores, punidores), como o nome já revela, são capazes de destruir não só a força alienígena, como também superar o desenvolvimento tecnológico desta. Além disso, eles despontam como os defensores do Universo, não apenas da cidade novaiorquina; seus poderes vão além do espaço terráqueo. Examinando as duas imagens, podemos ainda perceber a semelhança entre os bombeiros, heróis nacionais, em 11 de setembro de 2001; e os superheróis 'Vingadores', em meio aos destroços da mesma cidade; nesse caso, como mencionado, os últimos não só se marcam como heróis nacionais, mas universais, já que se percebem como defensores da Terra, em particular; e do Universo, em geral.

\footnotetext{
${ }^{10}$ Loki: Os Chitauri estão vindo. O que tenho a temer?

Homem de Ferro: Os Vingadores. É como nos chamamos. Somos uma equipe. Os heróis mais poderosos da Terra... e coisa e tal.

Loki: Sim, já os conheci.

HF: Leva um tempo para a gente se entender, admito. [...] Quando chegarem... e vão chegar. Será para ir atrás de você.

Loki: Eu tenho um exército.

[...........]

HF: Você não está entendendo. Não há nenhum trono. Não há uma versão disso em que você sai com êxito. Talvez seu exército venha e talvez seja demais para nós. Mas é tudo contra você. Porque, se não pudermos proteger a Terra, com certeza, nós a vingaremos. (grifos nossos)
} 


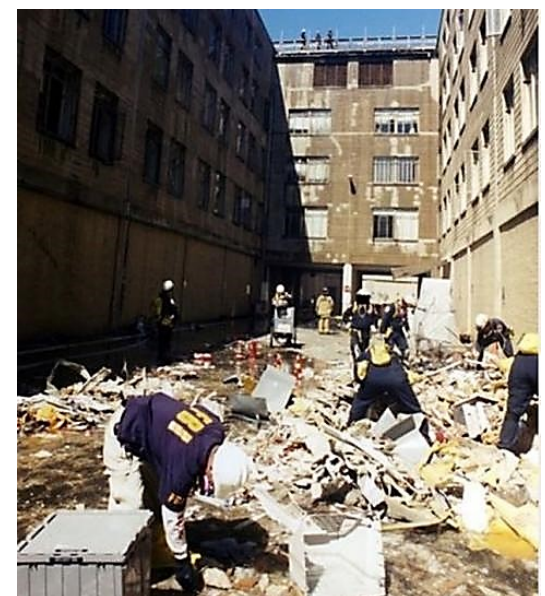

Figura 3 - SE4: Foto revelada pelo FBI dos atentados de 11 de setembro de 2001, em 2011

Fonte: Imagens das Torres Gêmeas. Disponível em: https://www.gentside.com.br/atentado/11-de-setembro-de2001-o-fbi-revela-fotos-exclusivas-dos-atentados-doworld-trade-center_art7420.html: Acesso em: 12 dez. 2019

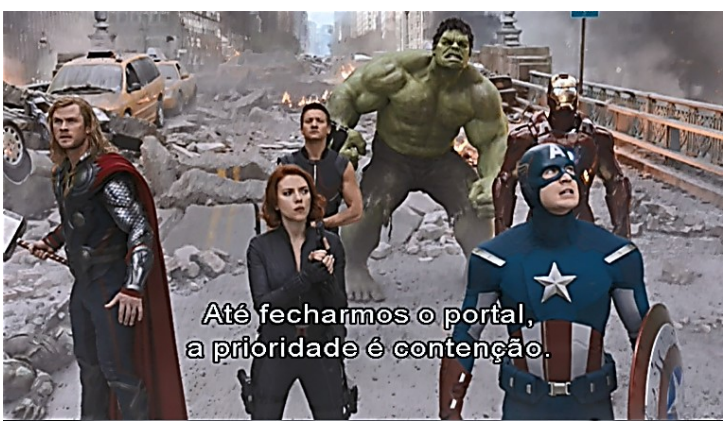

Figura 4 - SE5 (1:52:34): Os Vingadores em meio aos destroços resultantes da guerra contra os Chitauri e Loki

Fonte: OS VINGADORES: The Avengers. Direção Joss Whedon. Marvel Entertainment: Disney e Buena Vista. USA, 2012. [DVD] 2h23min, colorido.

Ademais, entendemos que, entre os humanos, os Chitauri e Loki há uma reconhecida luta não só pela apropriação do governo dos homens como pela disputa do poder/saber. Nesse sentido, no próximo item, apresentamos estudos referentes à ligação conhecimento/verdade/poder/subjetivação. E, como afirmado no decorrer dessa abordagem, objetivando estabelecer o diálogo entre a fundamentação teórica e o objeto de estudo, analisamos três sequências enunciativas.

\section{CONHECIMENTO, VERDADE, PODER, SUBJETIVAÇÃO}

Na sequência, trazemos Foucault ([1973] 2013), para quem um dos objetivos de pesquisas se refere à necessidade de mostrar a possibilidade de as práticas sociais engendrarem domínios de saber e, com efeito, verdades, não apenas concernentes ao aparecimento de novos objetos, conceitos, técnicas, mas à formação de novos sujeitos, de sujeitos do conhecimento. Esse filósofo discute, dessa forma, como foi possível construir um novo saber a partir das práticas de vigilância, de controle. Foucault levanta, então, duas hipóteses sobre a história da verdade: uma interna, relacionada à história da verdade sob o signo das ciências; outra externa, referente a outros lugares de formação da verdade, com "um certo número de regras de jogo definidas" ([1973] 2013), p. 20).

À luz do estudo da relação verdade/subjetivação, Foucault ([1973] 2013), retomando o pensamento nietzschiano, nega a preexistência de um sujeito do conhecimento, observando a contradição entre este pensamento e o kantiano. Para Kant, o ser humano possui estruturas a priori da intuição (conhecido como o 'apriorismo' kantiano), segundo as quais, antes de sua existência, o ser humano possui estruturas prontas, as de tempo e de espaço. Em outros termos, para este filósofo, o ser humano possui faculdades que tornam possível o conhecimento; com efeito, não poderíamos perceber nada fora dessas estruturas. 
É contrariando essa direção, relacionada à preexistência de um sujeito do conhecimento, que Foucault, ainda inspirado na obra de Nietzsche, reitera a diferença entre invenção (Erfindung) e origem (Upsprung), afirmando que a religião, a poesia, o ideal foram inventados, fabricados, produzidos por uma série de mecanismos, não têm origem. Do mesmo modo, o conhecimento foi inventado, não está inscrito na natureza humana. Como define Foucault ([1973] 2013, p. 25):

\footnotetext{
Foi por obscuras relações de poder que a poesia foi inventada. Foi igualmente por puras obscuras relações de poder que a religião foi inventada [...]. À solenidade de origem, é necessário opor um bom método histórico, a pequenez meticulosa e inconfessável dessas fabricações, dessas invenções.
}

Ainda fundamentado no pensamento nietzschiano, Foucault ([1973] 2013) argumenta que o mundo é um eterno caos, haja vista a ausência de ordem, de encadeamento, de formas, de beleza e de sabedoria; por conseguinte, não há leis da natureza. Defende, dessa forma, que o conhecimento deve lutar contra "[...] um mundo sem ordem, sem encadeamento, sem formas, sem beleza, sem sabedoria, sem harmonia, sem lei. [...] Não é natural à natureza ser conhecida" (FOUCAULT, [1973] 2013, p. 27).

Foucault ([1973] 2013) também alega que Nietzsche contesta as teses de Descartes, de Kant, na medida em que rompe com a harmonia, garantida por Deus, existente entre o conhecimento e as coisas a conhecer. Isso porque, para que Descartes pudesse provar que o conhecimento se fundamentava nas coisas do mundo, ele afirmou a existência de Deus, no centro do sistema do conhecimento. Tal perspectiva filosófica, ao ser contrariada, provoca uma ruptura teórica, a do conhecimento com a teologia, possibilitando a discussão sobre a dispersão do sujeito. E, ao provocar essa ruptura, a teoria nietzschiana traz para o interior do conhecimento, em sua raiz, o ódio, a luta, a relação de poder. Foucault ([1973] 2013, p. 26) assim define: “[...] O conhecimento, no fundo, não faz parte da natureza humana. É a luta, o combate, o resultado do combate e consequentemente o risco e acaso que vão dar lugar ao conhecimento". Mais adiante, ele ([1973] 2013, p. 33) acrescenta: "[...] o conhecimento é sempre uma relação estratégica em que o homem se encontra situado". Tal relação é que define o efeito do conhecimento: se parcial, oblíquo, perspectivo. Ainda de acordo com esse filósofo ([1973] 2013, p. 33): "Pode-se falar do caráter perspectivo do conhecimento porque há batalhas e porque o conhecimento é o efeito dessa batalha".

A relação entre o conhecimento, as práticas sociais, econômicas, políticas não são, porém, um impedimento para o sujeito do conhecimento. Ao contrário disso, é através delas que ocorre a subjetivação e, consequentemente, as relações de verdade. Nessa direção, Foucault defende: "Até na ciência encontramos modelos de verdade cuja formação deriva das estruturas políticas que não se impõem do exterior ao sujeito de conhecimento, mas que são, elas próprias, constitutivas do sujeito do conhecimento" ([1973] 2013, p. 35).

Lançando essas luzes sobre o objeto em estudo, constatamos também a relação entre o poder, a verdade/o conhecimento, os processos de subjetivação. Do início do filme a seu final, somos levados a essa discussão, quando o líder Chitauri conversa supostamente 
com Thanos, personagem que, na saga de "Os Vingadores", só aparece no terceiro filme, "Os Vingadores: Guerra Infinita" ${ }^{11 "}$. Inicialmente, os Chitauri põem em xeque o conhecimento dos humanos sobre o poder do Tesseract, colocando Loki, seu aliado, numa posição de superioridade quanto a esse saber/poder:

\begin{abstract}
( $\left.\mathrm{SE}_{6}(0: 00: 29)\right)$ : O Tesseract foi despertado. Ele está em um mundo pequeno, um mundo humano. Eles querem utilizar seu poder, porém nosso aliado conhece seu funcionamento como eles jamais conhecerão. Ele está pronto para liderar nosso exército, os nossos Chitauri o seguirão. Um mundo será dele. O universo, seu. E os humanos, o que poderão fazer senão perecer? (grifos nossos)
\end{abstract}

Sob a óptica do líder dos Chitauri, os humanos não têm a competência de Loki, resultando no extermínio dos humanos. Em outras palavras, a produção do saber tecnológico, armamentista dos humanos está aquém da dos alienígenas, discurso reiterado em vários filmes (além dos filmes da Marvel, exemplificamos "A 5 a Onda", 2016). Tal perspectiva é reiterada por Thor (defensor essencialmente da Terra), quando afirma, diante dos demais 'Vingadores' ( $\mathrm{SE}_{7}$ (1:12:24)): "O Tesseract pertence a Asgard. Nenhum humano é páreo para ele". Observamos uma disputa entre povos (humanos, Chitauri, asgardianos, super-heróis) e planetas, quanto ao saber usar esse objeto bélico, quanto à intensidade de seu poder. Toda a trama desse filme gira em torno da obtenção desse objeto bélico e o posterior governo da Terra, do Universo, a partir dele.

A $\mathrm{SE}_{6}$, acima apresentada, pode ser contrastada também com uma outra sequência enunciativa, correspondente às cenas pós-créditos, em que o líder dos Chitauri trava um novo diálogo com Thanos, em resposta ao ataque contra a Terra, advertindo-o de que é perigoso lutar com os humanos ( $\mathrm{SE}_{8}$ (2:15:10)): "Humanos. Não são os miseráveis acuados que nos prometeram. Eles resistem. São indisciplinados, portanto não podem ser governados. Desafiá-los é cortejar a morte". Se comparadas, essas três sequências enunciativas remetem à contraposição referente à subjugação (ao conhecimento, às armas alienígenas) versus resistência. Esta é representada pela Iniciativa Vingadores; não são humanos comuns, mas super-heróis salvaguardando todos os seres da Terra (e, em determinados filmes deste Universo, os de outros planetas). Nesse sentido, a imagem dos humanos continua como a de seres subjugados aos demais, considerados superiores, dentre os quais estão os super-heróis, partícipes de uma organização para além dos órgãos estatais, enfatizando, inclusive, a incompetência destes.

No final do filme, o Homem de Ferro e Hulk despontam como as mentes ilustres capazes de não só entenderem o mecanismo do Tesseract como também de construírem armas compatíveis com a tecnologia alienígena. Capitão América reitera a representação de dignidade, integridade, a competência de combate, associando-o à imagem de soldado criada por esse país. Viúva Negra pode reproduzir a figura do empoderamento feminino, tanto em relação à força física como às capacidades de persuasão, de ação. Finalmente, ao Gavião Arqueiro subjaz o discurso da capacidade de reagir ao controle do mal, com a

11 Entende-se, porém, que a tradução realizada é inadequada. O título deve ser traduzido como "Os Vingadores: Guerra do Infinito" (com o título em inglês: "Avengers: Infinity War"; não "Avengers: Infinite War"), já que o objeto em discussão são as joias do infinito. 
ajuda da Viúva Negra. Ele traz à tona também a imagem lendária do guerreiro portador do arco e flecha. Cada super-herói uma representação; a cada representação, uma geração de verdades, de subjetividades, a reiteração da personificação do bem.

Enfatizamos ainda a força, o poder da Torre Stark, representante do poderio tecnológico, científico, armamentista e, consequentemente, econômico-financeiro. Entendemos que, a partir das análises, há uma remissão sub-reptícia ao ataque terrorista das Torres Gêmeas, corroborando o diálogo entre o presente filme e esse acontecimento histórico.

E, se levarmos em conta o processo de subjetivação dos super-heróis, há uma reiteração de suas características heroicas, dada a vitória final. Nesse sentido, retomamos os argumentos de Foucault ([1973] 2013, p. 33), para quem "o conhecimento é o efeito dessa batalha". Somente a partir da necessidade de combater o desconhecido, nesse caso os alienígenas, os super-heróis produzem saberes compatíveis com o desenvolvimento tecnológico, armamentista de seres considerados mais poderosos, mais inteligentes. Em tese, todos estão em busca da justiça e, por isso, percebem-se autorizados a matar.

\section{CONSIDERAÇÕES FINAIS}

Inicialmente, explicamos o significado da pesquisa arqueológica, nos termos de Foucault (1997a), por ser um dos eixos em que se fundamenta a análise. Em síntese, tal perspectiva se interessa pela esfera discursiva, não pelo referente (considerado por Foucault (1997a), como objeto do historiador); abre as estruturas para as descontinuidades temporais, a dispersão, os desequilíbrios; pauta-se numa perspectiva de pluralização; rompe com o materialismo histórico. Em seguida, complementamos essa abordagem teórica apresentando os conceitos principais norteadores da análise: os dois aspectos do discurso, um linguístico; o outro, um campo estratégico, um operador. De igual modo, definimos enunciado, concretizado sob forma de qualquer registro, de natureza semiológica. A partir dessa definição, consideramos o filme um enunciado, analisando oito sequências enunciativas.

Ainda concernente à pesquisa arqueológica, analisamos os campos de saber mobilizados no objeto escolhido: a interligação entre os discursos religioso, mitológico, ufológico; o discurso tecnológico/armamentista (numa inter-relação com a física quântica); os conhecimentos referentes à história (em diferentes temporalidades). Da mesma maneira, à luz de Deleuze, Foucault, Gregolin, situamos o objeto como um dispositivo de poder, investigando no todo fílmico, na historicidade de seu entorno, as quatro dimensões apontadas por Deleuze.

Nas sequências enunciativas ( $\mathrm{SE}_{1}, \mathrm{SE}_{2}, \mathrm{SE}_{3}$ ), realizamos a análise resgatando os aspectos históricos, tecnológicos/armamentistas, sociais, religiosos. E constatamos que "Os Vingadores", enquanto um filme que alcança grandes escalas de veiculação de discursos, é capaz de proporcionar múltiplos processos de objetivação, de subjetivação. Ao remeter a acontecimentos ditos e esquecidos, no âmbito da história, da religião, do mito, ele aponta para a construção de novos acontecimentos, tensionando a memória e esquecimento; em virtude disso, proporciona o surgimento de novos discursos, a (re)produção de subjetividades. 
Também trabalhamos com o segundo eixo investigativo de Foucault, a pesquisa genealógica, abrangendo as práticas não discursivas. Nessa pesquisa, esse filósofo traz para o âmbito das análises as relações de poder, a produção de verdades. Situamos, nessa direção, os processos de subjetivação, de produção de saberes, relacionando-os às ponderações que Foucault ([1973] 2013) faz, sob o ponto de vista nietzschiano da invenção do conhecimento. Em consequência disso, instauram-se relações de ódio, a batalha, quanto às verdades resultantes desse processo. A partir dessa orientação, analisamos as sequências enunciativas ( $\left.\mathrm{SE}_{6}, \mathrm{SE}_{7}, \mathrm{SE}_{8}\right)$, constatando a subjugação dos humanos ao conhecimento de seres extraterrestes. Entretanto, na mesma medida, observamos a resistência de 'Os Vingadores', revelando não só o poder intelectual, mas também o econômico, armamentista, a força física. À luz dessas análises, estudamos a representatividade de cada Vingador e, por conseguinte, o seu poder quanto às imagens divulgadas.

Compreendemos, então, que esse filme apresenta, principalmente, a discussão acerca da detenção/obtenção do conhecimento, da tecnologia avançada, do poder das armas, compatíveis com guerras entre nações, entre mundos, em uma suposta busca da paz universal. Tudo isso em meio aos super-heróis, a deuses nórdicos, à Iniciativa dos Vingadores, reiterando o discurso segundo o qual o povo americano foi eleito por Deus para civilizar, agora, não somente a América, mas o Universo. Esses notáveis Vingadores rememoram, portanto, não só o poder econômico, político, armamentista dessa nação, mas a engenhosidade de seus heróis.

Consideramos ainda a definição de vingança do "Houaiss eletrônico" (2009): um "[...] ato lesivo, praticado em nome próprio ou alheio, por alguém que foi real ou presumidamente ofendido ou lesado, em represália contra aquele que é ou seria o causador desse dano; desforra, vindita". Verificamos, dessa forma, um apagamento do sentido de vingança, na medida em que eles despontam como os protetores da Terra, em busca de paz, de justiça.

Ao longo das análises, tentamos também responder às perguntas norteadoras da pesquisa: qual o papel dos discursos veiculados no UCM para a criação do imaginário dos sujeitos? Numa perspectiva arqueológica, questionamos a conexão entre a mídia e a 'história do presente'. Quanto à primeira pergunta, os discursos veiculados nesse/por esse Universo Cinematográfico proporcionam novos processos de subjetivação, tanto no interior de seus próprios enredos, como também relacionados aos espectadores, fiéis à observação da filmografia. Na medida em que rememoram acontecimentos históricos, inclusive no âmbito do jogo das imagens, instauram (ou reiteram) o ideal segundo o qual os Estados Unidos são capazes de superar as batalhas contra sua economia, seu conhecimento; um país formado por super-heróis, em múltiplos sentidos. Enfim, um país que, em tese, "protege" a Terra.

No que concerne à segunda pergunta, o estabelecimento da conexão entre a mídia e a 'história do presente', julgamos que essa mídia, como dispositivo de poder, possibilita constantemente a visibilidade da história oficial, do passado/do presente, a fim de garantir a (re)produção de sentidos sobre esses fatos, 'modelos de verdade advindos de estruturas políticas', nas palavras de Foucault ([1973] 2013, p. 35). Essa perspectiva, garantidora da tensão entre memória e esquecimento, salvaguarda o discurso formador da própria nação 
estadunidense, no sentido de asseverar o nacionalismo, a confiança desse povo, no caso, nos super-heróis. E, assim, assegura o discurso acerca da democracia estadunidense, da luta de seus heróis nacionais, em favor da realização do sonho americano. Tais discursos são repetidamente difundidos nesse/por esse Universo Cinematográfico, reiterando mundialmente a imagem de soberania desse povo. Inspiram os espectadores do mundo a pensar nesse projeto de sociedade como um modelo a ser seguido, com o consequente processo de homogeneização da história do presente, em relação a múltiplos povos e culturas.

\section{REFERÊNCIAS}

BERNARDET, J. O que é cinema. São Paulo: Nova Cultural/ Brasiliense, 1985.

CASTRO, E. Vocabulário de Foucault: um percurso pelos seus temas, conceitos e autores. Trad. Ingrid Müller Xavier. 2. Ed. Belo Horizonte: Autêntica, 2016.

DELEUZE, G. O que é um dispositivo? In: DELEUZE, G. O mistério de Ariana. Trad. Edmundo Cordeiro. Lisboa: Nova Vega/Passagens, 2015, p. 83-96.

FOUCAULT, M. A arqueologia do saber. Trad. Luiz Felipe Baeta Neves. Rio de Janeiro: Forense, 1997a.

FOUCAULT, M. Vigiar e punir: nascimento da prisão. Trad. Raquel Ramalhete. Petrópolis, RJ.: Vozes, 1997b.

FOUCAULT, M. A ordem do discurso. Trad. Laura Fraga de Almeida Sampaio. São Paulo: Edições Loyola, 2003.

FOUCAULT, M. Microfisisica do poder. Trad. Roberto Machado. Rio de Janeiro: Edições Graal, 2008.

FOUCAULT, M. [1969] O que é um autor? In: MOTTA, M. B. da (Org.). Ditos e escritos III. Estética: literatura e pintura, música e cinema. Trad. Inês Autran Dourado Barbosa. Petrópolis: Forense Universitária, 2009. p. 264 - 298.

FOUCAULT, M. [1976]. O discurso não deve ser considerado como... In: MOTTA, M. B. da (Org.). Ditos e escritos VII: Arte, epistemologia, filosofia, história da medicina. Trad. Vera Lúcia Avellar Ribeiro. Rio de Janeiro: Forense Universitária, 2011, p. 220-221.

FOUCAULT, M. [1977] Poder e saber. In: MOTTA, M. B. da (Org.). Ditos e escritos IV: Estratégia, poder-saber. Rio de Janeiro: Forense Universitária, 2012, p. 219-235.

FOUCAULT, M. [1977] Poderes e estratégias. In: MOTTA, M. B. da (Org.). Ditos e escritos IV: Estratégia, poder-saber. Rio de Janeiro: Forense Universitária, 2012, p. 236-246.

FOUCAULT, M. [1978] Diálogo sobre o poder. In: MOTTA, M. B. da (Org.). Ditos e escritos IV: Estratégia, poder-saber. Rio de Janeiro: Forense Universitária, 2012, p. 247 - 260.

FOUCAULT, M. [1973]. A verdade e as formas jurídicas. Trad. Eduardo Jardim e Roberto Machado. Rio de Janeiro: Nau, 2013.

GREGOLIN, M. do R. de F. V. Análise do discurso e semiologia: enfrentando discursividades contemporâneas. In: PIOVEZANI, C.; CURCINO, L.; SARGENTINI, V. (Org.). Discurso, semiologia e história. São Carlos: Claraluz, 2011. p. 83-105.

GREGOLIN, M. do R. de F. V. Discurso, história e a produção de identidades na mídia, 2016.

Disponível em: http://geadaararaquara.blogspot.com.br/2016/04/discurso-historia-e-producao-de.html Acesso em: 9 jul. 2017.

HOUAISS, A. Houaiss eletrônico: dicionário Houaiss da língua portuguesa. Rio de Janeiro: Ed. Objetiva, 2009.

LYNCH, R. A. A teoria do poder em Foucault. In: TAYLOR, D. Michel Foucault: conceitos fundamentais. Org. Dianna Taylor. Trad. de Fábio Creder. Petrópolis, RJ: Vozes, 2018. p. 23 - 40.

OS VINGADORES: The Avengers. Direção Joss Whedon. Marvel Enternainment: Disney e Buena Vista. USA, 2012. [DVD] 2h23min, colorido.

BARROS, Maria Emília de Rodat de Aguiar Barreto. Os vingadores: mobilização dos discursos da religião, do mito, da tecnologia, da história. Linguagem em (Dis)curso - LemD, Tubarão, SC, v. 21, n. 1, p. 51-69, jan./abr. 2021. 
Bíblia Online. Disponível em: https:/www.bibliaonline.com.br/acf/jo/14. Acesso em: 15 maio 2019.

Bilheteria do filme Os Vingadores (2012). Disponível em:

https://www.google.com.br/search?safe=active\&sxsrf=ACYBGNRh15MZGpU 3tgzbYkA5-

jueuYEEg\%3A1574546726609\&source $=$ hp\&ei=Jq3ZXeaRIpGgtQXduJuwBg\&q $=$ os + vingadores + the $+\mathrm{a}$ vengers+bilheteria\&oq=bilheteria + Os + Vingadores $\% 3 \mathrm{~A}+$ the $+\& g s \_\mathrm{l}=\mathrm{psy}-$ ab.1.0.0i22i30j0i333.1973.23166..27287...1.0..0.389.8311.2-26j4.....0....1..gwswiz.......0i131j0j0i70i251.RiFiphaeRFY . Acesso em: 23 nov. 2019.

Cetro de Loki. Disponível em: https://aminoapps.com/c/marvel-comics-amino-br/page/item/cetro-doloki/r0aL_r84HqI17WEdddW3zpD0BXxg7RjaLl Acesso: em 07 jul. 2019.

Cronologia Marvel. Disponível em:

https://www.instagram.com/p/Bu9ABOcgzwf/?igshid=1mwja194n6wwi Acesso: em 22 maio 2019.

Filmes da Marvel: https://observatoriodocinema.bol.uol.com.br/listas/2018/04/6-filmes-da-marvel-quevoce-precisa-ver-antes-de-assistir-a-vingadores-guerra-infinita Acesso: em 22 maio 2019.

Hidra (Marvel Comics). Disponível em:

https://pt.wikipedia.org/wiki/Hidra_(Marvel_Comics) Acesso em: 06 de jul. 2019.

Imagens das Torres Gêmeas. Disponível em: https://www.gentside.com.br/atentado/11-de-setembro-de2001-o-fbi-revela-fotos-exclusivas-dos-atentados-do-world-trade-center_art7420.html: Acesso em: 12 dez. 2019.

Inauguração do monumento 11 de setembro. Disponível em: https://sicnoticias.pt/mundo/2017-09-11-Japassaram-16-anos-desde-o-11-de-Setembro Acesso em: 12 dez. 2019.

Instituto Humanitas Unisinos. Disponível em: http://www.ihu.unisinos.br/172-noticias/noticias2012/508867-a-desigualdade-nos-estados-unidos-era-uma-vez-o-sonho-americano- Acesso em: 08 jul. 2019.

Livro de Jonas. Disponível em: https://pt.wikipedia.org/wiki/Livro_de_Jonas Acesso em: 16 maio 2019.

Loki. Disponível em: https://pt.wikipedia.org/wiki/Loki Acesso em: 03 nov. 2019.

Significado da Física Quântica: Disponível em: https:/www.significados.com.br/fisica-quantica/ Acesso em: 12 dez. 2019.

Vingadores. Disponível em: https://pt.wikipedia.org/wiki/Vingadores;

https://pt.wikipedia.org/wiki/The_Avengers_(filme_de_2012); http://www.adorocinema.com Acesso em: 22 maio 2019.

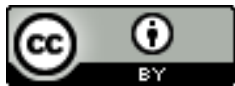

Este texto está licenciado com uma Licença Creative Commons Atribuição 4.0 Internacional.

BARROS, Maria Emília de Rodat de Aguiar Barreto. Os vingadores: mobilização dos discursos da religião, do mito, da tecnologia, da história. Linguagem em (Dis)curso - LemD, Tubarão, SC, v. 21, n. 1, p. 51-69, jan./abr. 2021. 